Case report

\title{
Young age - an unusual finding of Hürthle cell carcinoma
}

\author{
Laura Claudia Teodoriu*,1,2, Delia Gabriela Ciobanu-Apostol, ${ }^{2,3}$, Alexandru \\ Grigorovici ${ }^{2,4}$, Cristina Preda ${ }^{1,2}$
}

${ }^{1}$ Department of Endocrinology, "Sf. Spiridon" Emergency University Hospital, lași, Romania; ${ }^{2 “ G r i g o r e ~}$ T. Popa" University of Medicine and Pharmacy, lași, Romania; ${ }^{3}$ Department of Pathology, "Sf. Spiridon" Emergency University Hospital, laşi, Romania; ${ }^{4}$ Department of General Surgery IV, "Sf. Spiridon" Emergency University Hospital, Iaşi, Romania

\begin{abstract}
Hürthle cell carcinoma is a rare thyroid neoplasm which originates from the follicular epithelium of the thyroid gland and is considered a true rarity in young patients. A 30 year-old woman was admitted to our department with palpable anterior cervical mass due to enlarged thyroid. The ultrasound revealed a large thyroid nodule with central hypoechogenicity, peripheral hyperechogenicity and positive Doppler signal. The patient had no distinguishable lateral cervical lymphadenopathy. The TI-RADS calculation (thyroid image reporting data system) classified the nodule as TR4 (4 points), which indicated a fine needle aspiration biopsy (FNAB), declined by the patient. Total thyroidectomy was performed and the histological findings associated with immunohistochemical study revealed the diagnosis of Hürthle cell carcinoma with capsular and vascular invasion. Because the microscopic vascular invasion was $<4$ foci the patient was classified as low-risk group. Even so, due to the young age she was referred to radioactive iodine therapy for completion of curative treatment. This case illustrates the difficulties in the management of thyroid nodules with suspicious features on ultrasound, in the absence of FNAB exploration, and the unusual presence of Hürthle cell carcinoma in a young age patient, knowing the $6^{\text {th }}$ decade is the average age for this rare type of thyroid neoplasm.
\end{abstract}

Keywords: thyroid neoplasm; Hürthle cell carcinoma; thyroid cancer; young patient; aggressive treatment

\section{Introduction}

Hürthle cell carcinoma $(\mathrm{HCC})$ is a rare thyroid tumour described for the first time by Ewing in 1928. Among all the forms of differentiated thyroid carcinomas, HCC represents only $3.5-7 \%$, which makes it a true rarity [1, 2].

Hürthle cells, also known as oxyphil cells, can be observed in thyroid pathologies both benign and malignant. These cells are marked eosinophilic, large and polygonal with granular cytoplasm reflective of abundant mitochondria and are found in benign condition such as:

Received: July 2018; Accepted after review: December 2018; Published: December 2018.

${ }^{*}$ Corresponding author: Laura Claudia Teodoriu, Department of Endocrinology, "Sf. Spiridon" Emergency University Hospital, 1 Independentei Blvd, lași, Romania.

Email: lauraferaru89@yahoo.com autoimmune thyroiditis, Graves's disease and hyperplastic nodules. Oncocytic differentiation results in Hürthle cell neoplasia that can be an adenoma or a carcinoma. The differential diagnosis between these two entities is very difficult prior to surgical intervention. The clinical, ultrasonographic, and fine needle aspiration biopsy (FNAB) data are unable to accurately differentiate between Hürthle adenoma and carcinoma. Only the histological findings of the resection specimen represent the gold standard of diagnosis. The hallmarks of Hürthle carcinoma are the presence of capsular and/or vascular invasion [1].

\section{Case report}

A 30 year-old woman was admitted to our department with enlarged thyroid due to a right 
palpable mass discovered 3 months earlier. The medical history was not significant and the general clinical examination was normal. The thyroid ultrasound examination revealed a large nodule $(2 / 1.7 / 1.5 \mathrm{~cm})$ in the right lobe with peripheral hyperechogenicity, central hypoechogenicity and positive Doppler signal (Figure 1). No lateral cervical lymph nodes were detected on ultrasound investigation. The extra-nodular thyroid structure was isoechogenic with normal vascularization. The TI-RADS calculation (thyroid image reporting data system) classified the nodule in TR4 (4 points) which indicated a FNAB, but the patient refused this minimal invasive procedure. The hormonal profile revealed normal values for $\mathrm{TSH}=2.3 \mathrm{uUl} / \mathrm{ml}(0.4-4$ $\mathrm{uUl} / \mathrm{ml}), \mathrm{FT} 4=1.02 \mathrm{ng} / \mathrm{dl}(0.89-1.76 \mathrm{ng} / \mathrm{dl})$, AAT-TPO $=10 \mathrm{Ul} / \mathrm{ml}(<100 \mathrm{Ul} / \mathrm{ml})$ and for calcitonin $=3.11 \mathrm{pg} / \mathrm{ml}(0-11 \mathrm{pg} / \mathrm{ml})$.

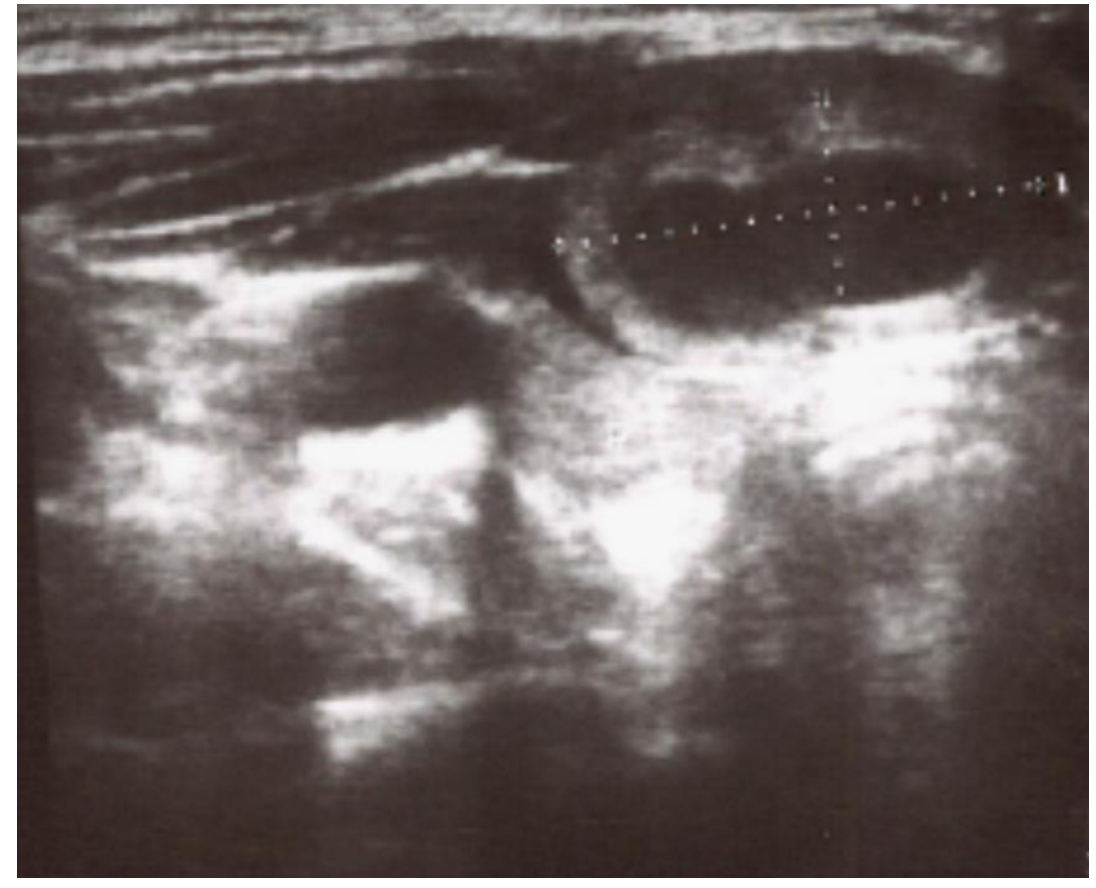

Fig. 1. Right thyroid nodule with central hypoechogenicity and peripheral hyperechogenicity.

Due to the large thyroid mass with suspicious ultrasound pattern and the patient's young age a surgical treatment was deemed as the best option. The patient underwent a total thyroidectomy. The postoperative course had a favorable evolution and the patient was discharged with no complication (hypocalcemia or recurrent laryngeal nerve paralysis). The histological report described: isthmus and right lobe containing a nodular specimen with polycyclic aspect measuring 1.5/ $1.2 / 0.7 \mathrm{~cm}$, with smooth, continuous capsule. Tumor cells were found and had solid and trabecular architecture, were polygonal, with granular eosinophilic cytoplasm and round, angular nuclei with evident nucleoli. Extensive areas of necrosis were also observed. The fine capsule was penetrated and vessels were invaded by tumor emboli ( 2 foci) (Figure 2). Immunohistochemical study supported the histological findings of vascular invasion. Immunostaining exposed: positive Cytokeratin 19 in tumor cells of vascular emboli (Figure 3a), with negative HBME-1 (Figure 3b), thereby differentiating HCC from papillary thyroid carcinoma, positivity for CD31 that confirms the presence of vascular invasion (Figure 4) and positivity for CD56- a neuroendocrine marker not commonly found in this type of thyroid carcinoma (Figure 5).

The pathological examination of the surgical specimen (histological and immunohistochemical) concluded with the diagnosis of Hürthle cell carcinoma with capsular and vascular invasion (2 foci), classifying the tumor as pT1bNx G1 LOV1Pn0. 


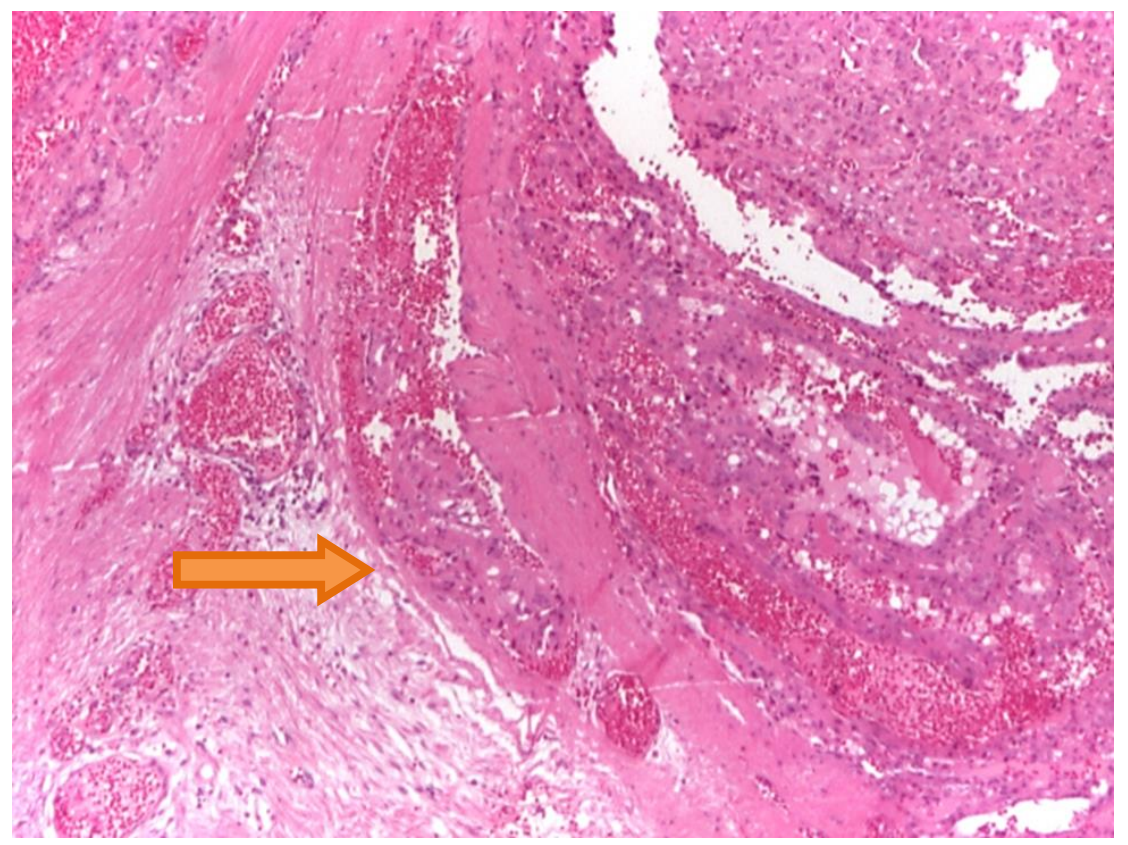

Fig. 2. Hürthle cell carcinoma with vascular invasion - intravascular tumor cells (HE, x40).

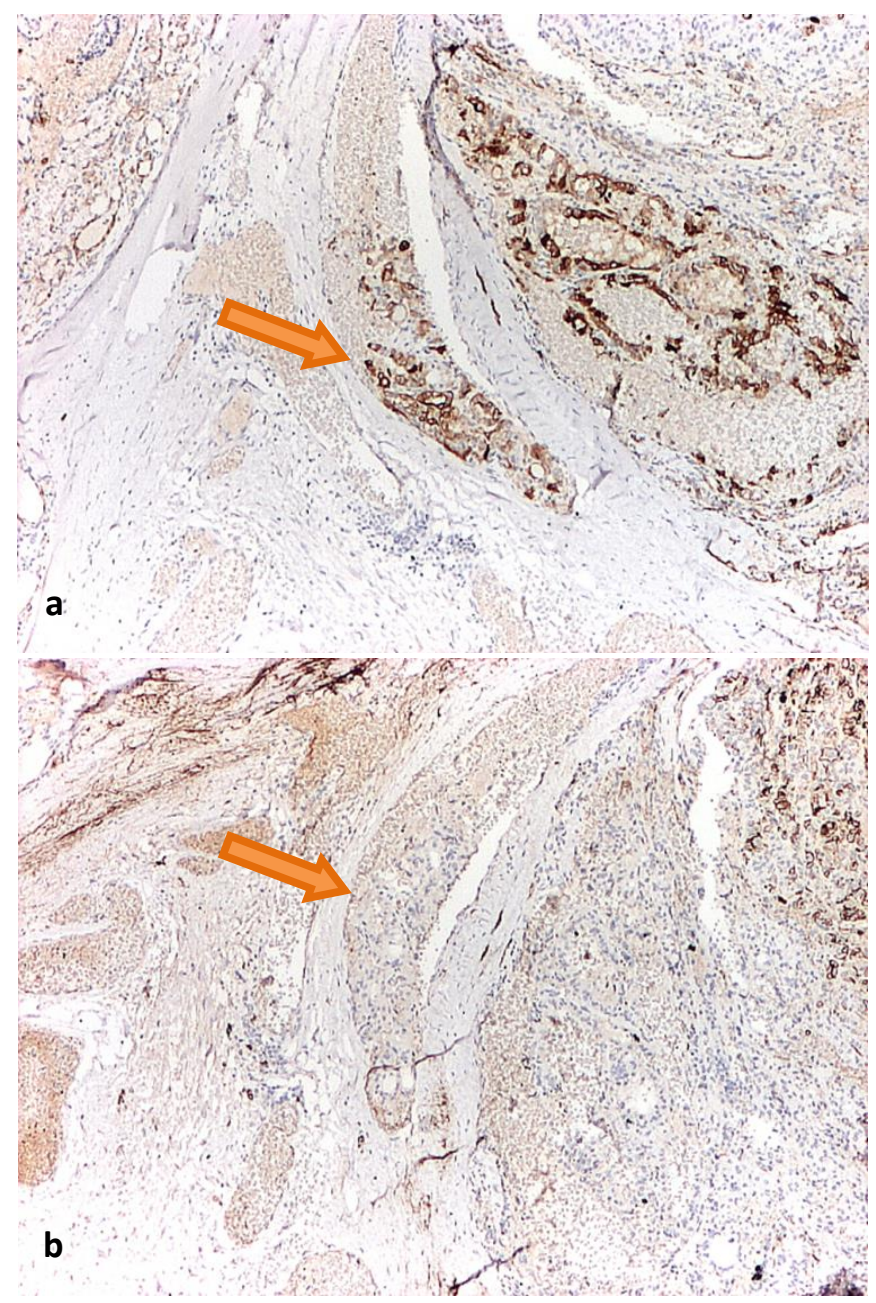

Fig. 3. Hürthle cell carcinoma with vascular invasion: (a) intravascular tumor cells are positive for CK19 (IHC, anti-CK19 Ab, x40); (b) tumor cells are negative for HMBE-1 (IHC, anti-HMBE-1 Ab, x40). 


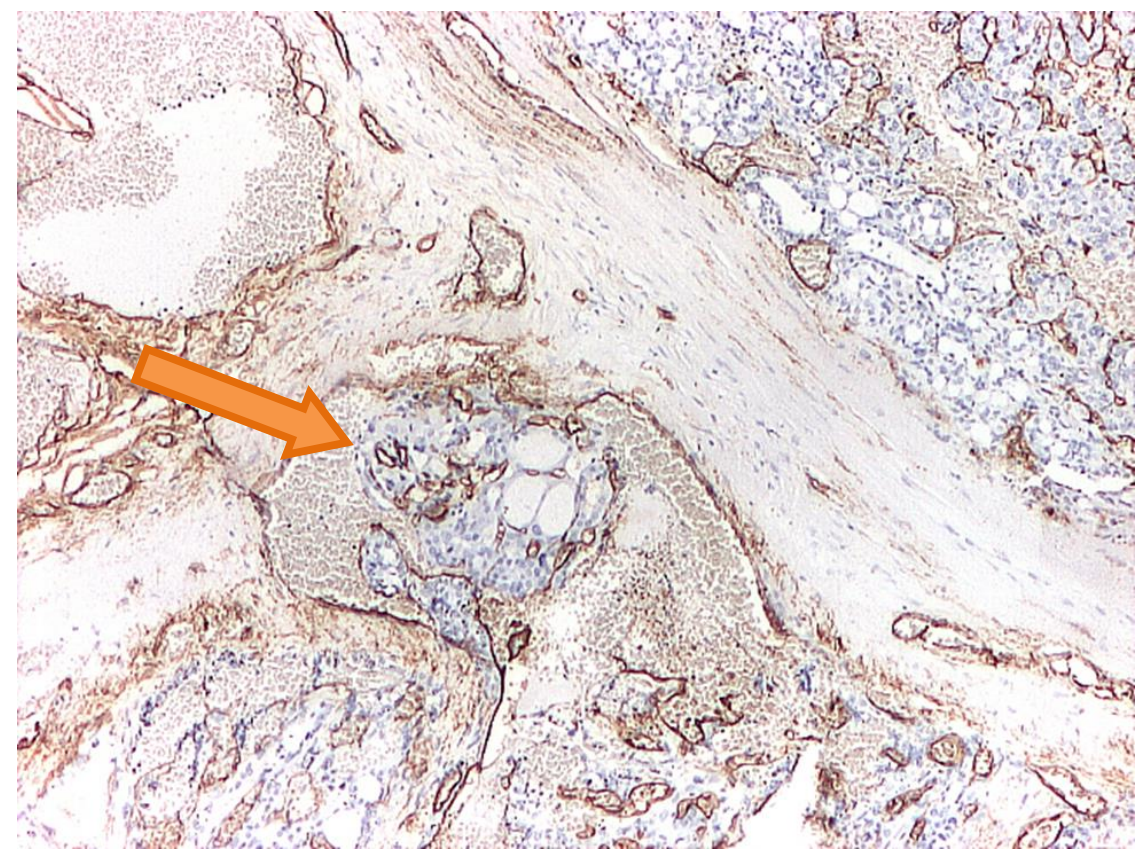

Fig. 4. Endothelial cells are positive for CD31, thus confirming vascular invasion (IHC, anti-CD31 Ab, x40).

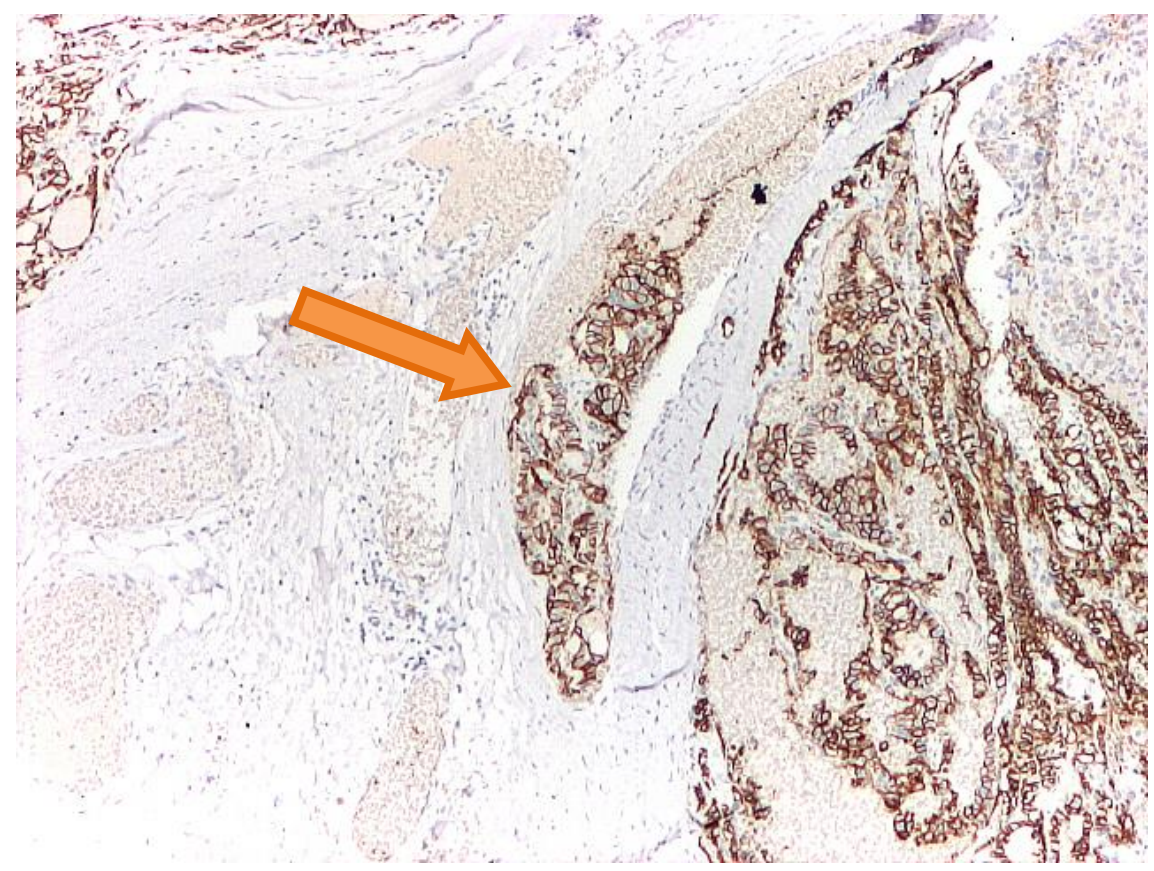

Fig. 5. Intravascular tumoral cells are positive for CD56 - neuroendocrine marker unusually found in HCC (IHC, anti-CD56 Ab, x40).

The patient was referred to radioactive iodine therapy (RAI) for completion of curative treatment, receiving $1.85 \mathrm{Gbq}{ }^{131} \mathrm{I}$, well tolerated by the patient, with no further complications. Substitutive treatment with levothyroxine was also initiated and the patient is under constant clinical, biological and echographic supervision.

\section{Discussions}

This case report illustrates the difficulties in the management of the thyroid nodules with suspicious ultrasound features, in the absence of FNAB exploration. The decision for surgery was justified, considering the histological diagnosis of thyroid carcinoma. Moreover, this 
type of thyroid neoplasia (Hürthle cell carcinoma) is very rare and uncommon in young patients. Patients are preponderantly diagnosed with Hürthle cell carcinoma in $6^{\text {th }}$ decade of life (average age of 54), in contrast to our patient which was diagnosed at a young age. The ratio between sexes is 3.6:1 female to male, this data corresponding to our case. HCC develops later than other thyroid malignancies, with a 10 years delay. Average tumor size at time of surgery ranges from 2.5$4.8 \mathrm{~cm}[3,4]$. In our patient's case, the tumor size was smaller.

Recent evidence described the unique pathological features of Hürthle cell carcinoma, different oncogenesis and clinical characteristics as compared to papillary and follicular carcinoma of the thyroid gland.

In Hürthle carcinoma, regions of chromosomes 5, 7, 12 and 17 had 11\% RAS mutation and no Pax8-PPARr rearrangements, in contrast with follicular carcinoma where $45 \%$ RAS mutation and 25 $60 \%$ Pax8- PPARr rearrangements were found [1, 2].

Histological findings classify HCC into minimally or widely invasive carcinoma. Tumors with capsular or vascular invasion $<4$ foci represent the minimally invasive variant of $\mathrm{HCC}$, while extensive vascular invasion $>4$ foci and extra- thyroidal extension represent the widely invasive variant. Some minimally invasive variants $(<4$ foci) were reported as being less aggressive, with good prognosis similar to HCC with no vascular invasion [1].

Previously, Hürthle carcinoma had worse prognosis reports than papillary and follicular carcinomas. Recent studies note a 92\% survival rate after curative surgical treatment [3].

Our patient met the criteria assigned by The National Comprehensive Cancer Network (NCCN) guidelines for HCC (2016): minimal vascular invasion described as a few microscopic foci $(<4)$, further classifying our patient as a low-risk group patient [5].

The adequate treatment for Hürthle cell carcinomas is the surgical method. There are ongoing debates regarding the use of radioiodine treatment, since Hürthle tumor cells have a lower affinity for radioactive iodine compared with other differentiated thyroid carcinomas. Postoperative radioactive iodine therapy remains controversial.

The American Thyroid Association (ATA) recommends RAI therapy for tumors larger than $1 \mathrm{~cm}$ following total thyroidectomy, while NCCN recommends RAl for tumors larger than $2 \mathrm{~cm}$ or in the presence of one or more of the following elements: vascular invasion, extrathyroidal extension, lymph node metastases, or elevated postoperative unstimulated thyroglobulin levels [5]. Our patient met the ATA recommendation for RAI therapy: tumor size was $>1 \mathrm{~cm}(1.5 / 1.2 \mathrm{~cm})$ and total thyroidectomy was performed.

It has been reported that 5-10 years survival was enhanced for patients who received RAI compared with those who did follow this course of treatment [5].

Although Hürthle cell histology is an independent risk factor for reduced 10 year survival, patients with HCC had an unusually good prognosis compared with papillary or follicular carcinoma, even after adjustment for age, type of curative treatment, extrathyroidal extension, nodal or distant metastases [6, 7].

This case is particular due to the young age of our patient with Hürthle cell carcinoma. knowing the $6^{\text {th }}$ decade is the average age for this rare type of thyroid neoplasm. Also, the therapeutical decision for surgery was unusual but justified in the context of the results reported by the histological assessment.

\section{Conclusions}

There are times when the best therapeutical decision is very difficult, particularly if important diagnostical data are missing (in our case the FNAB). Clinical judgment is very important and total thyroidectomy was the appropriate curative treatment for our patient. Adequate surgical treatment increases disease specific survival and decreases relapse rates.

Treatment management in our case report was prompt and aggressive. The young age represents an unusual feature for HCC, thus making the treatment for minimally invasive variant more aggressive than suggested by guidelines. 


\section{Consent}

Written informed consent was obtained from the patient for publication of this case report.

\section{References}

1. Ahmadi S, Stang $M$, Jiang $X$, Sosa JA. Hürthle cell carcinoma: current perspectives. Onco Targets Ther 2016; (9):6873-6884.

2. Donatini $G$, Beaulieu $A$, Castagnet $M$, Kraimps JL, Levillain P, Fromont G. Thyroid Hürthle cell tumors: research of potential markers of malignancy. J Endocrinol Invest 2016; 39(2):153-158.

3. Oluic B, Paunovic I, Loncar Z, et al. Survival and prognostic factors for survival, cancer specific survival and disease free interval in 239 patients with Hürthle cell carcinoma: a single center experience. BMC Cancer 2017; 17(1):371.

\section{Competing interests}

The authors declare that they have no competing interests.
4. Li $\mathrm{P}$, Liu $\mathrm{P}$, Zhang $\mathrm{H}$. Ultrasonic diagnosis for thyroid Hürthle cell tumor. Cancer Biomark 2017; 20(3):235-240.

5. Jillard CL, Youngwirth L, Scheri RP, Roman S, Sosa JA. Radioactive iodine treatment is associated with improved survival for patients with Hürthle cell carcinoma. Thyroid 2016; 26(7):959-964.

6. Xiong Y, Zhao Q, Li Z, et al. Propensity score matching analysis of the prognosis for the rare oxyphilic subtype of thyroid cancer (Hürthle cell carcinoma). Oncotarget 2017; 8(60):101362101371.

7. Tai $\mathrm{P}$, Korzeniowski M, Sadikov E, et al. Issues in managing Hürthle cell carcinoma of thyroid: a case report. Cureus 2017; 9(4):e1167. 